\title{
Actin-related proteins in Actinobacillus pleuropneumoniae and their interactions with actin-binding proteins
}

\author{
Alma L. Guerrero-Barrera, ${ }^{1} \dagger$ Mireya de la Garza, ${ }^{1}$ Ricardo Mondragón, ${ }^{3}$ \\ Claudia García-Cuéllar ${ }^{1,4}$ and Magdalena Segura-Nieto ${ }^{2}$
}

Author for correspondence: Magdalena Segura-Nieto. Tel: +52 46239600 ext. 665/413. Fax: +52 46245849 . e-mail:msegura@irapuato.ira.cinvestav.mx

\footnotetext{
1 Departamento de Biología Celular, Centro de Investigación y de Estudios Avanzados del IPN, Apartado Postal 14-740, México, DF 07000, Mexico

2 Departamento de Ingeniería Genética de Plantas, Centro de Investigación y de Estudios Avanzados del IPN Apartado Postal 629, Irapuato, Gto. 36500, Mexico

3 Departamento de Inmunología, Escuela Nacional de Ciencias Biológicas IPN, Prolongación de Carpio y Plan de Ayala s/n, México DF 11340, Mexico

4 División de Investigación Básica, Instituto Nacional de Cancerología, San Fernando No 22, Tlalpan, DF 14000, Mexico
}

\begin{abstract}
A group of prokaryotic actin-related proteins (PARP) with an $M_{\mathrm{r}}$ of 43000 was detected in Actinobacillus pleuropneumoniae. These proteins were enriched by a depolymerization/polymerization cycle, under similar conditions to those used to polymerize muscle actin, and purified by affinity chromatography on a DNase I-Sepharose column. Three isoforms of A. pleuropneumoniae PARP (Ap-PARP) with pl values of 5.8, 6.15 and 6.2 were detected. Ap-PARP were recognized by four different anti-actin antibodies (one anti-muscle and three anti-cytoplasmic isoforms). Ap-PARP were also recognized by antibodies against Anabaena variabilis PARP (Av-PARP) and against actin-binding proteins such as $\alpha$-actinin and spectrin, and also by monoclonal antibody against heatshock cognate protein 70 (Hsc70). Specific binding of phalloidin to Ap-PARP was detected both in permeabilized cells and in vitro. Purified Ap-PARP can polymerize under similar conditions to those required for skeletal muscle actin polymerization and the filaments formed appear to be decorated with myosin subfragment-1 (S1) as observed by transmission electron microscopy. The amino acid composition of Ap-PARP revealed more similarities to muscle $\gamma$-actin and the cytoplasmic $\beta$-actin isoform than to eukaryotic actin-related proteins.
\end{abstract}

Keywords: prokaryotic actin-related proteins, actin-related proteins, actin-binding proteins, cytoskeleton-like structure, Actinobacillus pleuropneumoniae

\section{INTRODUCTION}

Evidence from genetic and ultrastructural studies suggests that bacteria have proteins which are analogous to those that form microfilaments and microtubules in eukaryotes, and that these bacterial proteins might form a cytoskeleton-like structure with similar functions in different kinds of cells (Mayer et al., 1998; Margolin, 1998; Sharpe \& Errington, 1999). A major cytoskeletallike protein of bacteria is FtsZ, which is ubiquitous in eubacteria and is also found in archaea and chloroplasts.

\footnotetext{
†Present address: Departamento de Biología Molecular de Plantas, Instituto de Biotecnología, Universidad Nacional Autónoma de México, Apartado Postal 510-3 CP 62250, Cuernavaca, Mor, Mexico.

Abbreviations: $A B P$, actin-binding proteins; $A R P$, actin-related proteins; $C D$, cytochalasin D; Hsc, heat-shock cognate protein; Hsp, heatshock protein; PARP, prokaryotic actin-related proteins; S1, myosin subfragment-1; TRITC, tetramethylrhodamine isothiocyanate; $A p$, Actinobacillus pleuropneumoniae; Av, Anabaena variabilis.
}

FtsZ localizes early at the division site to form a ringshaped septum (Addinall et al., 1996; Bauman \& Jackson, 1996). This septum is required for the mechanochemical process of membrane constriction. FtsZ is a GTPase with weak sequence homology to tubulin, although its three-dimensional structure is similar to the structure of $\alpha$ - and $\beta$-tubulin (Lu et al., 1998; Löwe \& Amos, 1998; Nogales et al., 1998). Chromosomal segregation requires a driving force. This problem was initially approached by genetic screening of conditional segregation mutants and revealed the involvement of MukB protein. In Escherichia coli the MukB protein has been demonstrated to participate in the process of chromosomal partition and it has a domain structure reminiscent of the eukaryotic motor proteins kinesin and myosin. In vitro studies have demonstrated that FtsZ stimulates the nucleotide turnover of MukB (Hiraga, 1993; Lockhart \& Kendrick-Jones, 1998). In E. coli, nine proteins have been recognized as being essential for assembly of the cell-division septum. One 
of these proteins is FtsA which co-localizes in vivo with FtsZ, as demonstrated by tagging each protein with green fluorescent protein (Addinall et al., 1996; Ma et al., 1996). FtsA has been predicted to belong to the actin family and is present in different cell compartments depending on its phosphorylation state. The phosphorylated form is in the cytoplasm and binds ATP, while the non-phosphorylated form is membrane bound and does not bind ATP. Using the sequence-pattern-search method, a correlation of FtsA with a family of ATPbinding proteins that includes DnaK, heat-shock cognate protein 70 (Hsc70), sugar kinases and actin has been found (Bork et al., 1992; Sánchez et al., 1994). Other actin-like proteins have been identified in different bacteria and were proposed to form a kind of cytoskeleton whose physiological role is not yet understood (Minkoff \& Damadian, 1976; Neimark, 1977; Nakamura \& Watanabe, 1978; Göbel, 1983; Sioud et al., 1987; Barnett \& Cunningham, 1992; Labbé et al., 1996; Norris et al., 1996; Mayer et al., 1998).

The prokaryotic actin-related proteins (PARP) from Anabaena species and E. coli share epitopes with smooth muscle actin (Guerrero-Barrera et al., 1995, 1996), and actin-like proteins from Synechocystis spp. share antigenic reactivity with distinct antibodies that recognize actin regions known to interact with proteins crosslinking actin filaments (Usmanova et al., 1998). Actinobacillus pleuropneumoniae, the etiological agent of porcine pleuropneumonia is a Gram-negative bacterium that has been intensively investigated. Special attention has been paid to A. pleuropneumoniae virulence factors and the production of toxin-neutralizing antibodies to protect pigs against porcine pleuropneumonia (Haesebrouck et al., 1997; Prideaux et al., 1999). However, no studies have been done on the cell biology of this pathogen. To study the putative cytoskeleton of $A$. pleuropneumoniae, we searched for the presence of molecules which behave like actin. Here we report on the purification and characterization of three actinrelated proteins (ARP) present in A. pleuropneumoniae. These proteins show similar behaviour to eukaryotic actin in several of their biochemical and immunological properties.

\section{METHODS}

Materials. All reagents were analytical grade from Sigma, except for ampholytes and Sepharose $4 \mathrm{~B}$ which were from Pharmacia Biotech.

Bacteria. A. pleuropneumoniae strain 35 (serotype 1) was isolated from a lung abscess of a pig with acute porcine pleuropneumonia (Negrete-Abascal et al., 1994). Cultures were maintained on brain heart agar (Difco) with $10 \mu \mathrm{g}$ NAD $\mathrm{ml}^{-1}$. Bacteria for extracts were grown to stationary phase in brain heart infusion broth with $10 \mu \mathrm{g} \mathrm{NAD} \mathrm{ml}{ }^{-1}$ for $48 \mathrm{~h}$ at $37^{\circ} \mathrm{C}$ with constant shaking (150 r.p.m.). A. pleuropneumoniae cells from a $500 \mathrm{ml}$ culture were harvested and washed twice with PBS $(0 \cdot 145 \mathrm{M}$ sodium chloride, $0 \cdot 15 \mathrm{M}$ sodium phosphate, $\mathrm{pH} 7 \cdot 4$ ) by centrifugation at $10000 \mathrm{~g}$ at $4{ }^{\circ} \mathrm{C}$ for $10 \mathrm{~min}$. Cells were washed five times by centrifugation with cold acetone $\left(-20^{\circ} \mathrm{C}\right)$ and dried to a powder at room temperature.
A. pleuropneumoniae PARP (Ap-PARP) depolymerization and polymerization. The method of Pardee \& Spudich (1982) was used with some modifications. Acetone-dried cells $(500 \mathrm{mg}$ ) were resuspended in $500 \mu \mathrm{l}$ protease inhibitor cocktail (62.5 mM Tris/HCl, pH 7.4, $5 \mathrm{mM}$ diisopropyl fluorophosphate, $2 \mathrm{mM} N$-ethylmaleimide, $10 \mathrm{mM}$-hydroxymercuribenzoate, $5 \mathrm{mM}$ tosyl-L-lysine chloromethyl ketone and $2 \mu \mathrm{M}$ leupeptin). This cell suspension was diluted in $10 \mathrm{ml}$ actin depolymerization buffer $(2 \mathrm{mM}$ Tris $/ \mathrm{HCl}, \mathrm{pH} 7 \cdot 4$, $0.2 \mathrm{mM} \mathrm{Na}{ }_{2}$ ATP, $2 \mathrm{mM} \mathrm{CaCl}{ }_{2}$ and $0.5 \mathrm{mM} \beta$-mercaptoethanol) and incubated for $2 \mathrm{~h}$ at $4{ }^{\circ} \mathrm{C}$ with gentle stirring. Following incubation, the suspension was centrifuged at $25000 \mathrm{~g}$ at $4{ }^{\circ} \mathrm{C}$ for $30 \mathrm{~min}$ and the pellet was discarded. A range of $1-5 \mathrm{mM} \mathrm{Na}_{2} \mathrm{ATP}$ was used to optimize $A p$-PARP polymerization. PARP were polymerized by adjusting the supernatant to contain $50 \mathrm{mM} \mathrm{KCl}, 2 \mathrm{mM} \mathrm{MgCl}_{2}, 5 \mathrm{mM}$ EGTA and $5 \mathrm{mM} \mathrm{Na}{ }_{2} \mathrm{ATP}$ (polymerization buffer A) and gently stirring for $2 \mathrm{~h}$ at $37^{\circ} \mathrm{C}$. The preparation was then centrifuged at $180000 \mathrm{~g}$ for $1.5 \mathrm{~h}$ at $4^{\circ} \mathrm{C}$ and the supernatant was discarded. The pellet contained polymerized Ap-PARP filaments. Ap-PARP filaments were solubilized in $100 \mu \mathrm{l} 1 \%$ SDS, $2 \% \quad \beta$-mercaptoethanol, $4 \mathrm{M}$ urea. Precipitation according to Wessel \& Flügge (1984) resulted in a detergent-free Ap-PARP pellet.

Ap-PARP purification by binding to DNase I. Ap-PARP from the detergent-free pellet were purified by affinity chromatography on a DNase I column (Guerrero-Barrera et al., 1996).

Ap-PARP purification by electroelution. The detergent-free Ap-PARP pellet was also fractionated by preparative Tricine/SDS-PAGE (15\% gels) as described by Schägger \& von Jagow (1987). Part of the gel was used to identify $A p$ PARP by Western blot analysis with different antibodies against actin and actin-binding proteins (ABP). The rest of the gel was stained with Coomassie blue and the corresponding PARP bands were cut out and electroeluted in an ElectroEluter model 422 (Bio-Rad). The electroelution buffer was $50 \mathrm{mM} \mathrm{NH} \mathrm{HCO}_{3}, 0 \cdot 1 \%$ SDS. Electroelution was performed for $5 \mathrm{~h}$ at $10 \mathrm{~mA}$ per tube as described in the Bio-Rad manual.

Electrophoretic analysis. Two methods were used for onedimensional SDS-PAGE: the first was the Laemmli (1970) method using $10 \%$ gels; the second was the Tricine/SDSPAGE method of Schägger \& von Jagow (1987) using $15 \%$ gels. Electrophoresis was performed in a Mighty-Small II SE250 Cell (Hoefer) at $100 \mathrm{~V}$ for 1 or $2.5 \mathrm{~h}$. Gels were stained with $0 \cdot 2 \%$ Coomassie blue R250 in destaining solution $(10 \%$ methanol, $10 \%$ acetic acid in water).

Two-dimensional (2D) gel electrophoresis was done according to O'Farrell (1975).

Western blotting. Ap-PARP were separated by Tricine/SDSPAGE as described above and transferred to Immobilon-P (Millipore) or nitrocellulose membranes in a Mini Trans-Blot Electrophoretic Transfer Cell (Bio-Rad) at $253 \mathrm{~mA}$ for $45 \mathrm{~min}$. The transfer buffer contained $10 \mathrm{mM}$ CAPS, $0.4 \mathrm{mM}$ DTT and $10 \%$ methanol $(\mathrm{pH} 11)$. For immunodetection, the following antibodies were used: polyclonal mouse antibody against Anabaena variabilis PARP (Av-PARP) and monoclonal mouse anti-rat brain actin (Guerrero-Barrera et al., 1996), polyclonal rabbit anti-C-terminal actin (A 2066, synthetic peptide SGPSIVHRKCF; Sigma), monoclonal mouse anti- $\alpha$-smooth muscle actin (A 2547; Sigma), polyclonal rabbit anti-profilin- $\gamma$-actin complex from calf spleen (M. SeguraNieto \& U. Lindberg, unpublished data), monoclonal mouse anti-Hsc70 (Sigma), polyclonal rabbit anti- $\alpha$-actinin and polyclonal rabbit anti-spectrin (kit Cyto-2; Sigma). In all cases peroxidase-labelled protein $\mathrm{A}$ was used to detect antibody 
binding. The immune reaction was revealed with 4-chloronaphthol in a Mini-Protean II Multiscreen Apparatus (Bio$\mathrm{Rad})$. All procedures were done at room temperature.

\section{Phalloidin binding}

Whole cells. A. pleuropneumoniae cells were treated with phalloidin labelled with tetramethylrhodamine isothiocyanate (TRITC) as described previously (Guerrero-Barrera et al., 1996). For the assays, $10 \mathrm{ml}$ of a stationary-phase culture was used. Readings were taken in a spectrofluorometer (PerkinElmer Luminiscence Spectrometer L5 50B) at an excitation wavelength of $550 \mathrm{~nm}$ and emission wavelength of $574 \mathrm{~nm}$. Non-treated cells were used as negative control.

Ap-PARP. DNase I-affinity-purified Ap-PARP (100 $\mu \mathrm{g})$ was incubated for $2 \mathrm{~h}$ at $37^{\circ} \mathrm{C}$ in $500 \mu \mathrm{l}$ polymerization buffer $\mathrm{A}$ with $50 \mathrm{ng}$ TRITC-phalloidin; the drug excess was removed following precipitation of $A p$-PARP using the method of Wessel \& Flügge (1984). The TRITC-phalloidin filamentous $A p$-PARP (F-Ap-PARP) precipitate was resuspended in $1 \mathrm{ml}$ PBS. As negative control, PARP were incubated with unlabelled phalloidin, and as positive control skeletal muscle Factin was incubated with TRITC-phalloidin. The interaction was measured with a spectrofluorometer as described above.

\section{Electron microscopy}

Negative staining of PARP. The Ap-PARP detergent-free pellet $(100 \mu \mathrm{g})$ was resuspended in $500 \mu \mathrm{l}$ polymerization buffer $\mathrm{A}$ and incubated for $2 \mathrm{~h}$ at $37^{\circ} \mathrm{C}$. Ten microlitres of this reaction mixture containing F-Ap-PARP was laid on nickel grids covered with Formvar and settled for $10 \mathrm{~min}$ at room temperature. Then the samples were fixed with $2.5 \%$ glutaraldehyde and washed with polymerization buffer $\mathrm{A}$. Samples were contrasted with $0 \cdot 5 \%$ uranyl acetate, $\mathrm{pH} 7 \cdot 4$. Skeletal muscle actin was used as positive control. The observations were made with a JEOL 2000 EX transmission electron microscope at $80 \mathrm{kV}$.

Decoration of F-Ap-PARP with myosin subfragment-1 (S1). Ten microlitres of the above polymerized F-Ap-PARP mixture was deposited on a carbon Formvar-coated nickel grid and allowed to settle for $10 \mathrm{~min}$ at room temperature. Then, $10 \mu \mathrm{l} \mathrm{S} 1$ $\left(25 \mathrm{mg} \mathrm{ml}^{-1}\right.$ ) in polymerization buffer $\mathrm{A}$ (without $\mathrm{Na}_{2} \mathrm{ATP}$ ) was added before incubation overnight at $4{ }^{\circ} \mathrm{C}$. Samples were fixed and washed, and observations were made with the electron microscope as described above.

Amino acid composition. The electroeluted Ap-PARP were hydrolysed in $6 \mathrm{M} \mathrm{HCl}$ for $24 \mathrm{~h}$ at $110{ }^{\circ} \mathrm{C}$ under vacuum and the amino acid composition was determined as described by Bidlingmeyer et al. (1984).

\section{RESULTS AND DISCUSSION}

The presence of PARP in A. pleuropneumoniae was investigated as an initial step in the study of its putative cytoskeletal structure. To identify and characterize ARP, the following five classical criteria for actin identification in eukaryotic cells were used.

\section{Enrichment by one}

\section{depolymerization/polymerization cycle and purification by binding to DNase I}

One of the ways to obtain and enrich functional eukaryotic actin is through depolymerization/ polymerization cycles. This method was used with $A$. pleuropneumoniae cell extracts, and a polypeptide band with an $M_{\mathrm{r}}$ of 43000 in SDS-PAGE was enriched as shown in Fig. 1(a), lane 3. This $M_{\mathrm{r}}$ is similar to that of skeletal muscle actin (Fig. 1a, lane 1). Using this method it was possible to identify and purify Ap-PARP from cell extracts that had polymerization capability similar to eukaryotic actin. The Ap-PARP were also enriched from the cell-free culture filtrate of exponential-phase viable cells (data not shown), apparently as a product of secretion from the bacteria.

The specific binding of DNase I to the majority of eukaryotic actins is the most common criterion used to identify this conserved protein family (Lazarides \& Lindberg, 1974). PARP from several bacterial species (Guerrero-Barrera et al., 1996), including Ap-PARP, have this property. The purity of Ap-PARP obtained after affinity chromatography on a DNase I column was observed by two-dimensional electrophoretic analysis (Fig. 1b). The physiological significance of the actinDNase I interaction is unknown, but it has been exploited as a method for actin purification. The $A p$ PARP-DNase I interaction also provides a one-step purification procedure. Ap-PARP bind to DNase I under the same conditions as muscle G-actin.

\section{Biochemical characterization}

(a) $\boldsymbol{M}_{\mathrm{r}}$ and pl. Ap-PARP have an $M_{\mathrm{r}}$ of 43000 (Fig. $1 \mathrm{a}, \mathrm{b}$ ), distinct from that reported for other actin-like proteins, e.g. 60000 for Streptococcus pyogenes (Barnett \& Cunningham, 1992) and E. coli (Guerrero-Barrera et al., 1996), and 56000 for Synechococcus spp. (Labbé et al., 1996). The Ap-PARP displayed three isoforms with $\mathrm{pI}$ values of 5.80, 6.15 and 6.20 (Fig. 1b). These isoforms are more acidic than PARP from Anabaena variabilis and $E$. coli (Table 1), but less acidic than actins from other species (Garrels \& Gibson, 1976; Herman, 1993). The Ap-PARP pI values are closer to those of Arp2 and Arp3 reported by the ExPASy WWW server (April, 1998). Arp1 is closer in pI, structure and amino acid sequence to skeletal muscle actin isoform (Herman, 1993; Schroer et al., 1994; Mullins et al., 1996).

(b) Amino acid composition. The amino acid composition of Ap-PARP reveals closer similarities to actin from different sources than ARP from Saccharomyces cerevisiae and Acanthamoeba castellanii (Table 2). On the other hand, there are clear differences in the glycine content. The level of glycine is relatively high in ApPARP as opposed to actin isoforms and ARP (Table 2). It is possible that the high glycine content of Ap-PARP might partially be caused by contamination during its extraction, although the electrophoretic method used to separate Ap-PARP contains Tricine buffer. Tricine is a derivative of glycine (Schägger \& von Jagow, 1987) and we cannot rule out the possibility that some glycine could be generated during the electrophoresis, which might interact with the protein. The complete amino acid composition of PARP will be certified when either the primary protein sequences or the encoding region of the genes becomes known.

Comparison of Ap-PARP amino acid composition 
(a)

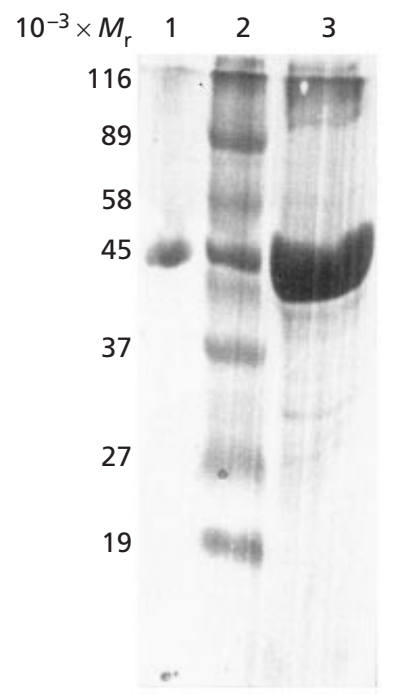

(b)

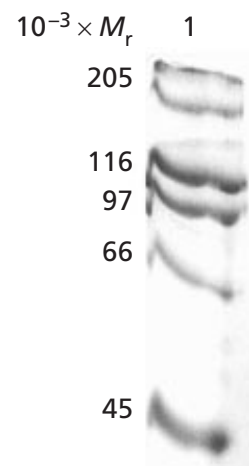

IF

Fig. 1. Electrophoretic pattern of Ap-PARP in (a) one and (b) two dimensions. (a) Tricine/SDS-PAGE (15\% gel) of skeletal muscle actin (lane 1) and Ap-PARP enriched by a depolymerization/polymerization cycle (lane 3). Lane 2, molecular mass markers. (b) Isoelectric focusing (IF) and SDS-PAGE (SDS) (10\% gel) of DNase-I-purified Ap-PARP showing the following pI values: (i) 5.80, (ii) $6 \cdot 15$ and (iii) 6.20. Lane 1, molecular mass markers.

Table 1. Comparison of Ap-PARP with other PARP, ARP, actin and Hsp70 (Hsc70) from different species

\begin{tabular}{|c|c|c|c|c|}
\hline \multirow[t]{2}{*}{ Protein } & \multirow[t]{2}{*}{$10^{-3} \times M_{\mathrm{r}}$} & \multicolumn{3}{|c|}{ pI } \\
\hline & & $(1)$ & $(2)$ & $(3)$ \\
\hline $\begin{array}{l}\text { A. pleuropneumoniae } \\
\text { PARP }\end{array}$ & 43 & $5 \cdot 80$ & $6 \cdot 15$ & $6 \cdot 20$ \\
\hline E. coli PARP* & 60 & $6 \cdot 60$ & $6 \cdot 65$ & $6 \cdot 70$ \\
\hline $\begin{array}{l}\text { Anabaena variabilis } \\
\text { PARP* }\end{array}$ & 45 & $6 \cdot 40$ & $6 \cdot 50$ & $6 \cdot 80$ \\
\hline Hsp70 (Hsc70)† & 70 & $5 \cdot 37$ & $5 \cdot 49$ & $5 \cdot 53$ \\
\hline $\mathrm{ARP} \ddagger$ & $48-60$ & $5 \cdot 40$ & $5 \cdot 50-6 \cdot 23$ & $5 \cdot 30-5 \cdot 82$ \\
\hline Actin $\mathbb{S}$ & $43-48$ & (a) $5 \cdot 40$ & ( $\beta) 5 \cdot 42$ & $(\gamma) 5 \cdot 44$ \\
\hline
\end{tabular}

*Guerrero-Barrera et al. (1996).

† (1) Human Hsc70, (2) chicken Hsp70 and (3) bovine Hsc70 (ExPASy WWW server, April, 1998).

‡(1) Arp1, (2) Arp2 and (3) Arp3 (ExPASy WWW server, April, 1998).

\Garrels \& Gibson (1976); ExPASy WWW server (April, 1998).

through a search on the ExPASy WWW server (April, 1998) revealed no homology with cytoplasmic bacterial proteins. Similarities were seen with the glucose-1phosphatase of E. coli and with several pilus chaperone proteins like PapD, AfaB and YopN from Yersinia pseudotuberculosis. The search also revealed similarity with several muscle proteins such as $\alpha$-skeletal muscle actin and $\alpha$-smooth muscle actin from different animal species, and skeletal muscle myosin light-chain and troponin-C/-I from cardiac and skeletal muscle. No homology was seen with ARP. (c) Toxin binding. Phalloidin binding to polymerized actin (F-actin) is a biochemical characteristic that all actins share. This is a stoichiometric interaction of one molecule of phalloidin to two actins. This toxin stabilizes actin filaments and prevents its depolymerization by agents such as DNase I, ultrasonication and proteolytic degradation (Vandekerckhove et al., 1985; Miyamoto et al., 1986; Sheterline et al., 1998). This binding is inhibited by cytochalasin $\mathrm{D}(\mathrm{CD})$, a toxin which binds both to monomeric actin and to the barbed end of actin filaments. CD binds at a stoi- 
Table 2. Comparison of the amino acid composition of Ap-PARP with that of $\beta$ - and $\gamma$-actin and ARP

Data for actins and ARP are from the ExPASy WWW server (April, 1998). ND, Not determined.

\begin{tabular}{|c|c|c|c|c|c|c|}
\hline $\begin{array}{l}\text { Amino } \\
\text { acid }\end{array}$ & PARP & $\beta$-Actin & $\gamma$-Actin & $\begin{array}{l}\text { Saccharomyces } \\
\text { cerevisiae Arp2 }\end{array}$ & $\begin{array}{l}\text { Acanthamoeba } \\
\text { castellanii Arp2 }\end{array}$ & $\begin{array}{l}\text { Acanthamoeba } \\
\text { castellanii Arp3 }\end{array}$ \\
\hline Asx & $7 \cdot 67$ & $8 \cdot 30$ & $8 \cdot 24$ & $9 \cdot 28$ & $9 \cdot 28$ & $7 \cdot 96$ \\
\hline Glx & $14 \cdot 49$ & $10 \cdot 70$ & $10 \cdot 10$ & $10 \cdot 05$ & $10 \cdot 05$ & $10 \cdot 54$ \\
\hline Ser & $7 \cdot 25$ & $6 \cdot 40$ & $6 \cdot 65$ & $4 \cdot 12$ & $4 \cdot 12$ & $5 \cdot 15$ \\
\hline His & $1 \cdot 57$ & $2 \cdot 40$ & $2 \cdot 40$ & $1 \cdot 30$ & $1 \cdot 30$ & $2 \cdot 57$ \\
\hline Gly & $19 \cdot 53$ & $7 \cdot 50$ & $7 \cdot 71$ & 6.70 & $6 \cdot 70$ & $7 \cdot 02$ \\
\hline Thr & $3 \cdot 16$ & 6.70 & $6 \cdot 65$ & $4 \cdot 12$ & $4 \cdot 12$ & $5 \cdot 15$ \\
\hline Ala & $5 \cdot 25$ & $7 \cdot 70$ & $7 \cdot 98$ & $5 \cdot 67$ & $5 \cdot 67$ & $6 \cdot 32$ \\
\hline Pro & $5 \cdot 04$ & $5 \cdot 00$ & $5 \cdot 00$ & $4 \cdot 90$ & $4 \cdot 90$ & $6 \cdot 01$ \\
\hline Tyr & $2 \cdot 41$ & $4 \cdot 00$ & $3 \cdot 72$ & $3 \cdot 87$ & $3 \cdot 87$ & $3 \cdot 40$ \\
\hline Arg & $3 \cdot 47$ & $4 \cdot 80$ & $5 \cdot 32$ & $6 \cdot 44$ & $6 \cdot 44$ & $5 \cdot 40$ \\
\hline Val & $7 \cdot 25$ & $5 \cdot 90$ & $5 \cdot 32$ & $9 \cdot 02$ & $9 \cdot 02$ & $7 \cdot 96$ \\
\hline Met & $1 \cdot 26$ & $4 \cdot 30$ & $4 \cdot 26$ & $3 \cdot 35$ & $3 \cdot 35$ & $2 \cdot 34$ \\
\hline Cys & $\mathrm{ND}$ & $1 \cdot 60$ & $1 \cdot 86$ & $2 \cdot 61$ & $2 \cdot 06$ & $1 \cdot 87$ \\
\hline Ile & $4 \cdot 00$ & $7 \cdot 50$ & $7 \cdot 71$ & $5 \cdot 41$ & $5 \cdot 41$ & $7 \cdot 26$ \\
\hline Leu & $7 \cdot 56$ & $7 \cdot 50$ & $7 \cdot 44$ & $9 \cdot 02$ & $9 \cdot 02$ & $5 \cdot 39$ \\
\hline Phe & $2 \cdot 74$ & $3 \cdot 20$ & $3 \cdot 20$ & $5 \cdot 67$ & $5 \cdot 67$ & $4 \cdot 92$ \\
\hline Lys & $7 \cdot 35$ & $5 \cdot 00$ & $5 \cdot 00$ & $7 \cdot 47$ & $7 \cdot 47$ & 6.79 \\
\hline
\end{tabular}

Table 3. Spectrofluorometric detection of $C D$ and phalloidin binding to permeabilized A. pleuropneumoniae cells

\begin{tabular}{|lr|}
\hline Sample & $\begin{array}{c}\text { Emission }\left(\lambda_{574}\right) \\
\left(\text { excitation } \lambda_{550}\right)\end{array}$ \\
\hline Cells incubated with TRITC-phalloidin & $75 \cdot 01$ \\
Cells preincubated with phalloidin and then incubated with TRITC-phalloidin & $0 \cdot 35$ \\
Cells incubated with CD & $0 \cdot 29$ \\
Cells preincubated with CD and then incubated with TRITC-phalloidin & $18 \cdot 70$ \\
\hline
\end{tabular}

Table 4. Spectrofluorometric measurement of $C D$ and phalloidin binding to F-Ap-PARP

\begin{tabular}{|lc|}
\hline Sample & $\begin{array}{c}\text { Emission }\left(\lambda_{574}\right) \\
\left(\text { excitation } \lambda_{550}\right)\end{array}$ \\
\hline F-Ap-PARP $(200 \mu \mathrm{g})$ preincubated with phalloidin and then incubated with TRITC-phalloidin & $0 \cdot 20$ \\
F- $A p$-PARP $(200 \mu \mathrm{g})$ incubated with TRITC-phalloidin & $6 \cdot 90$ \\
F-Ap-PARP $(200 \mu \mathrm{g})$ preincubated with CD and then incubated with TRITC-phalloidin & $0 \cdot 20$ \\
Muscle actin $(100 \mu \mathrm{g})$ preincubated with phalloidin and then incubated with TRITC-phalloidin & $0 \cdot 22$ \\
Muscle actin $(100 \mu \mathrm{g})$ incubated with TRITC-phalloidin & $8 \cdot 5$ \\
Muscle actin $(100 \mu \mathrm{g})$ preincubated with CD and then incubated with TRITC-phalloidin & $0 \cdot 25$ \\
\hline
\end{tabular}

chiometry of one molecule per filament, thus inhibiting monomer exchange and resulting in depolymerization (Sheterline et al., 1998). These two drugs were used to test for F-Ap-PARP both in permeabilized cells and in vitro. Table 3 shows the results of specific TRITCphalloidin binding to permeabilized A. pleuropneumoniae cells. This interaction is blocked when these cells are preincubated with either unlabelled phalloidin or CD. The specific binding of F-Ap-PARP to
TRITC-phalloidin was also measured in vitro with proteins purified by DNase I affinity chromatography, using the same strategy as above. This specific interaction is inhibited by preincubation of F-Ap-PARP with either unlabelled phalloidin or $\mathrm{CD}$ and measured by spectrofluorometry (Table 4). As a positive control skeletal muscle F-actin was incubated with TRITCphalloidin and this interaction was also inhibited by prior incubation with $\mathrm{CD}$ or unlabelled phalloidin 
Table 5. Effect of various chemicals on the polymerization of Ap-PARP and rabbit skeletal muscle actin

\begin{tabular}{|lccc|}
\hline Chemical & Concentration $(\mathbf{m M})$ & Ap-PARP $(\mathbf{2 0 0} \boldsymbol{\mu g})^{* *}$ & Actin $(\mathbf{2 0 0} \boldsymbol{\mu g})^{* *}$ \\
\hline $\mathrm{KCl}$ & 50 & + & + \\
$\mathrm{CaCl}$ & 2 & - & - \\
$\mathrm{MgCl}_{2}$ & 2 & + & + \\
$\mathrm{EGTA}$ & 5 & + & + \\
$\mathrm{ATP}$ & $1-5$ & + & + \\
$\mathrm{ATP}$ & $0 \cdot 2$ & - & - \\
\hline
\end{tabular}

$*+$, Contributes to polymerization; - , inhibits polymerization and contributes to depolymerization.

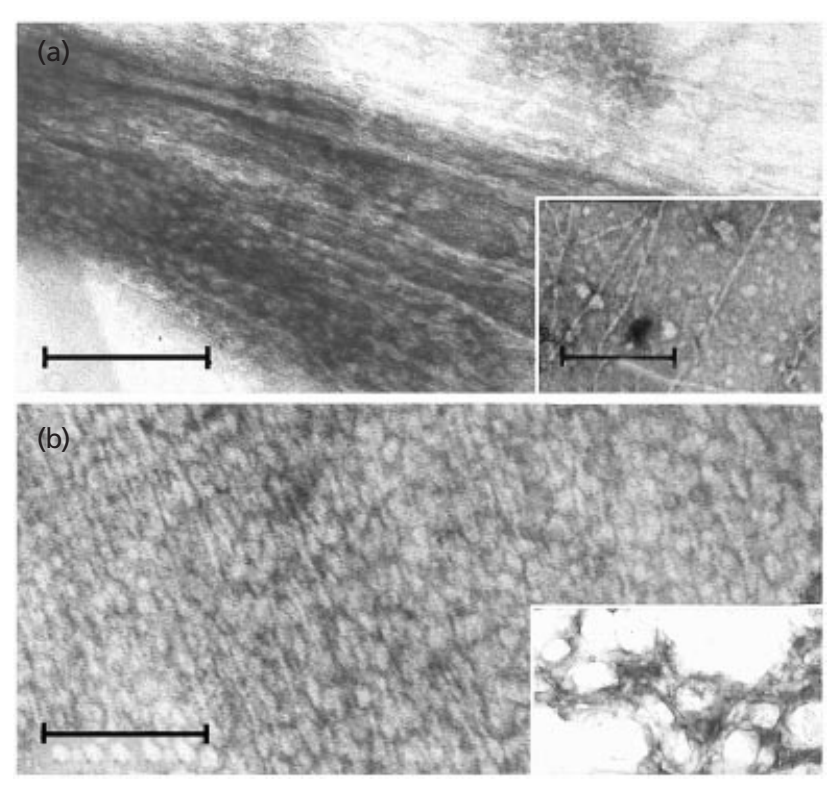

Fig. 2. Electron micrographs of filamentous Ap-PARP. Negative staining of (a) rabbit skeletal muscle F-actin (the inset shows single filaments) and (b) filamentous Ap-PARP (the inset shows the 'amorphous' structure). Bars, $200 \mathrm{~nm}$.

(Table 4). These data corroborate the observations made with permeabilized cells.

(d) ATP concentration. Table 5 shows a summary of the effects of various chemicals that inhibit or induce $A p$ PARP polymerization. The ionic strength and ATP concentration were the same as those used to polymerize skeletal muscle actin (Spudich \& Watt, 1971). The polymerization of PARP was done at twice the concentration of that used in the case of skeletal muscle actin, although PARP can also polymerize at the same concentration (data not shown).

\section{F-Ap-PARP ultrastructural analysis}

Transmission electron microscopy analysis of F-ApPARP under polymerization conditions showed two kinds of structures: one apparently similar to muscle F-actin, with filaments of 5-7 nm (Fig. 2b) (cf. muscle F-actin; Fig. 2a), and the other corresponding to an 'amorphous' network which may be due to the higher PARP concentration or to a variation in PARP filament organization (Fig. 2b, inset).

\section{Binding to DNase I and S1}

DNase I is an ABP which has been used to characterize the three-dimensional structure of G-actin (Kreuder et al., 1984; Kabsch et al., 1990). All PARP studied thus far have the capacity to bind DNase I under the same conditions as actin. This suggests that $A p$-PARP have a similar three-dimensional DNase I binding site to actin.

Actin and myosin form one of the major motor protein complexes in all eukaryotic cells. Most of the studies on myosin interaction with actin during force generation involve the use of mammalian fast muscle myosin II or its functional proteolytic fragments S1 and HMM, together with mammalian skeletal muscle actin. Each myosin head has similar actin-binding ATPase domains but different tail regions. Also, each myosin head may bind to two adjacent molecules of actin in the filament during the cross-bridge cycle. The most stable conformation is the rigor conformation which exists at the end of the cross-bridge cycle. This conformation can be experimentally 'frozen' by removal of ATP necessary to release the myosin head (Andreev \& Borejdo, 1991).

S1 binds to filaments of Ap-PARP (Fig. $3 b$ ) in a similar fashion to skeletal muscle actin (Fig. 3a). This interaction shows that filaments of Ap-PARP expose similar S1-binding sites to vertebrate actin. This observation suggests that $A p$-PARP filaments might have the ability to interact with myosin-like molecules from the bacteria in vivo, probably participating in intrabacterial motility, bacterial cell division and nucleoid segregation, as has been suggested by Casaregola et al. (1990). Although in A. pleuropneumoniae there have been no studies describing the presence of motor-like proteins as yet, the evidence from studies in different bacteria suggests that motor-like proteins are ubiquitous (Melby et al., 1998).

MukB in E. coli and the structural maintenance of chromosome proteins (SMC) found in almost all bacteria, archaea and eukaryotes are involved in chromosome partition. These proteins have a domain structure reminiscent of eukaryotic motor proteins similar to kinesin and myosin. They form homodimers 

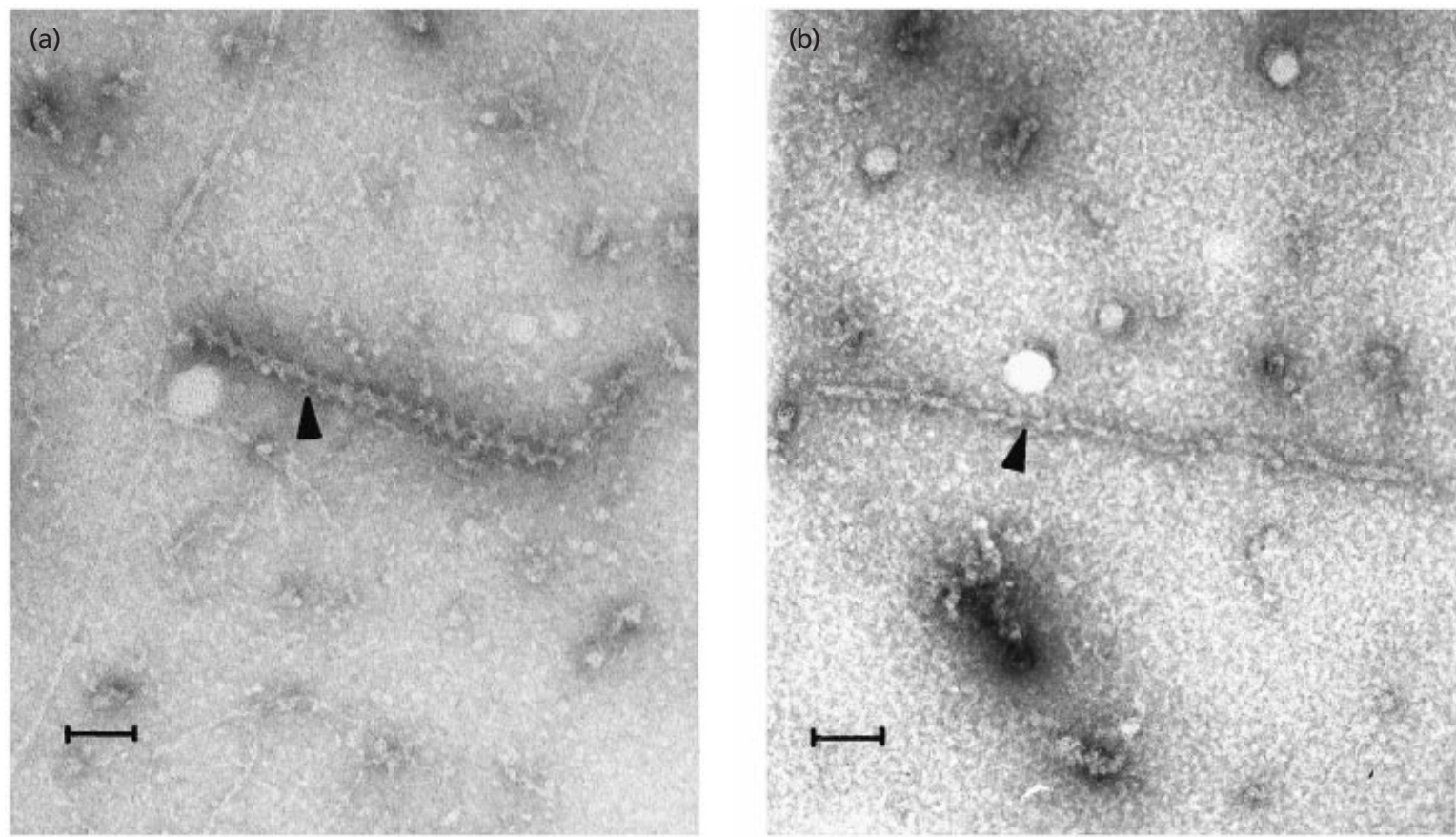

Fig. 3. Decoration of filamentous actin and filamentous Ap-PARP with $\mathrm{S} 1$. (a) Rabbit muscle actin. (b) Ap-PARP. The arrowheads point to the microfilament decorated with S1. Bars, $100 \mathrm{~nm}$.

having both DNA- and ATP/GTP-binding activities (Melby et al., 1998). A construct encoding the first 342 residues of MukB (Muk342) generates a fragment with properties of the motor domain of kinesin and is capable of decorating microtubules in a similar manner to kinesin. Analysis of the stoichiometry demonstrated an interaction of one Muk342 fragment per one tubulin monomer (Lockhart \& Kendrick-Jones, 1998). These results strongly suggest that MukB has a role in force generation. This type of in vitro experiment has not been done with F-actin filaments to see if Muk342 can interact with actin filaments in a similar manner to S1 (Fig. 3a).

Recent studies have completely overturned the classical view of chromosome segregation in bacteria. Far from being a passive process involving gradual separation of the chromosomes, there appears to exist an active, possibly mitotic-like machinery (Sharpe \& Errington, 1999; Melby et al., 1998). MukB and SMC proteins from Bacillus subtilis function in chromosome condensation and some other aspects of DNA processing (Niki et al., 1992; Lockhart \& Kendrick-Jones, 1998; Melby et al., 1998). These findings support the idea that prokaryotes might have a cytoskeletal-like structure involved in fundamental cellular functions as in eukaryotes.

\section{Immunological recognition of Ap-PARP by different antibodies}

Ap-PARP have several properties shown above which should be sufficient to consider them as members of the actin family. To reinforce this statement, other criteria were used, e.g. their recognition with different anti-actin antibodies and anti-ABP antibodies.

Ap-PARP obtained after one polymerization cycle were fractionated in a Tricine/SDS-PAGE gel, blotted and reacted with polyclonal antibodies against $A v$-PARP (Fig. 4, lane 2) and four different anti-actin antibodies (Fig. 4, lanes 3, 4, 5 and 8). All antibodies gave a positive reaction, showing that $A p$-PARP have epitopes similar to those present in different actins. On the other hand, the positive recognition of $A p$-PARP by two anti-ABP antibodies against $\alpha$-actinin and spectrin, both from chicken gizzard (Fig. 4, lanes 6 and 7), suggests structural similarities to eukaryotic actin molecules as well. This cross-reaction between actin and ABP was not nonspecific, since antibodies against filamin, vimentin, tropomyosin and myosin did not recognize any epitope on Ap-PARP (data not shown). On the other hand, the immunoelectron microscopic studies of prokaryotes of various taxonomic affiliations (archaea and bacteria) have shown a network made up of 'protein fibrils'. These fibrils are composed of proteins which exhibit cross-reactivity with the anti-actin antibody used in Fig. 4 , lane 5 (C terminus of actin). The network seems to be located around the cytoplasm close to the periphery of all the cells (Mayer et al., 1998). These authors propose the existence of a prokaryotic cytoskeleton that might function to preserve the shape of different prokaryotes.

Ap-PARP was also recognized by a monoclonal antiHsc70 antibody (Fig. 4, lane 9). This result reflects common epitopes in both proteins. Hsc70 shares a common structural fold and a nucleotide binding site with actin. It appears more likely that actin, Hsc70, 


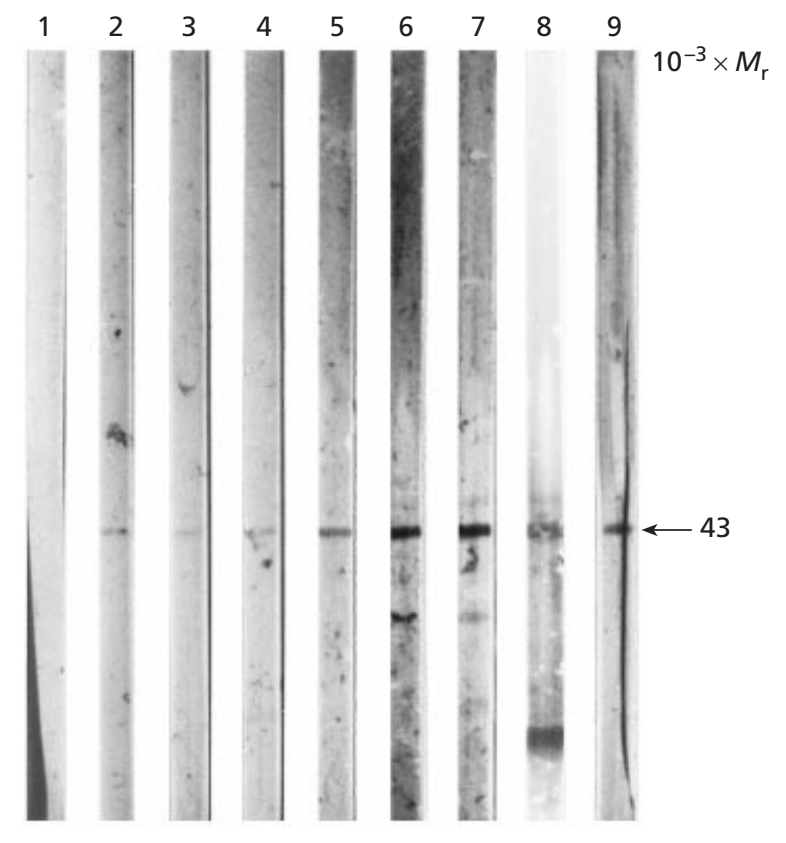

Fig. 4. Western blot of filamentous Ap-PARP enriched by a depolymerization/polymerization cycle. Lanes: 1, negative control reaction with protein A-peroxidase; 2-9, Ap-PARP recognized by anti-Av-PARP (2), monoclonal anti-rat brain actin (3), polyclonal anti- $\alpha$-smooth muscle actin (4), polyclonal anti-Cterminal synthetic peptide (5) anti- $\alpha$-actinin (6), anti-chicken spectrin (7), anti-calf spleen profilin- $\gamma$-actin complex (8) and monoclonal anti-Hsc70 (9).

hexokinase, glycerol kinase, and perhaps the prokaryotic cell cycle proteins (FtsA, MreB, StbA) and E. coli phosphatases, are the product of divergent evolution from a common ancestor of a single-domain molecule (Flaherty et al., 1991; Bork et al., 1992; Sánchez et al., 1994; Kabsch \& Holmes, 1995). The results from the Western blot analysis with Ap-PARP compared with data obtained from other PARP (Guerrero-Barrera et al., 1996) are shown in Table 6.
Since Minkoff \& Damadian (1976) reported actin-like proteins in prokaryotes, this has been confirmed by others (Rosenbusch et al., 1976; Neimark, 1977; Beck et al., 1978; Nakamura \& Watanabe, 1978; Sioud et al., 1987; Barnett \& Cunningham, 1992; Labbé et al., 1996; Guerrero-Barrera et al., 1996). However, there are no sequence data available on either the proteins or the gene to reveal a relationship with actin. Preliminary Southern blot studies of A. pleuropneumoniae DNA hybridization with actin probes of Taenia solium were negative (data not shown) (probes from Campos et al., 1990). Similar results were obtained for S. pyogenes (Barnett \& Cunningham, 1992). In the case of the complete genome sequence of Haemophilus influenzae, Mycoplasma genitalium and E. coli, actin sequences were not found (Fleischmann et al., 1995; Wahl et al., 1994; Koonin et al., 1996). Although there is an absence of data at the molecular level showing DNA homology between PARP and actin, the biochemical evidence suggests that PARP are ancestral actin-like protein candidates. It is possible that although homology of both the gene and the protein of PARP to eukaryotic actin could be low, its three-dimensional structure could be similar, as in the case of FtsZ and tubulin. FtsZ and tubulin have a common structural core with identical folding (including $10 \beta$-strands surrounded by $10 \alpha$ helices) (Nogales et al., 1998; Löwe \& Amos, 1998).

Other cytoskeleton-like components have been found in prokaryotic cells; e.g. myosin-like protein from E. coli (Nakamura \& Watanabe, 1978), $M$ protein in $S$. pyogenes, which has amino acid sequence homology with coiled-coil proteins similar to tropomyosin and myosin-like proteins (Manjula \& Fiscetti, 1986; Manjula et al., 1985, 1991; Mische et al., 1987; Barnett $\&$ Cunningham, 1992), and $\alpha$-actinin-like proteins in cyanobacterium Spirulina platensis (Usmanova et al., 1998). Thus, PARP as well as ABP might have existed before the emergence of eukaryotic cells. It is clear that many more cytoskeletal-like proteins in bacteria remain to be found and studied at the biochemical, genetic and

Table 6. Recognition of PARP by monoclonal and polyclonal antibodies against actin and ABP

\begin{tabular}{|lccc|}
\hline Antibody & \multicolumn{3}{c|}{ PARP $^{*}$} \\
\cline { 2 - 4 } & Ap & Av & Ec \\
\hline Av-PARP & + & + & + \\
C-terminal synthetic peptide & + & + & + \\
$\alpha$-Smooth muscle actin & + & - & - \\
Brain actin & + & + & + \\
Calf spleen profilin- $\gamma$-actin complex & + & + & + \\
Chicken gizzard $\alpha$-actinin & + & - & - \\
Chicken spectrin & + & - & - \\
Bovine brain Hsc70 & + & ND & + \\
\hline
\end{tabular}

*Data for Anabaena variabilis $(A v)$ and $E$. coli $(E c)$ are from Guerrero-Barrera et al. (1996). ND, Not determined. 
subcellular level to understand their organization and participation in the dynamics of the prokaryotic cell.

\section{ACKNOWLEDGEMENTS}

We thank the Electron Microscopy Unit of the Cell Biology Department of the National Center of Research and Advanced Studies of the National Politechnic Institute (CINVESTAVIPN). We thank Professor Uno Lindberg and Dr Roger Karlsson for their helpful comments, and June Simpson for her criticisms of the manuscript. We thank Aurora Verver for the amino acid composition analysis. We also thank Magda E. Reyes and Esteban Molina for technical assistance. A.L.G. was supported by the credit scholarship No. 85546 from the National Mexican Council for Science and Technology (CONACyT). This work was supported by CONACyT grants 1462-N9207 (M.G.) and 4096P-N (M.S.).

\section{REFERENCES}

Addinall, S. G., Bi, E. \& Lutkenhaus, J. (1996). FtsZ ring formation in fts mutants. J Bacteriol 178, 3877-3884.

Andreev, O. A. \& Borejdo, J. (1991). The myosin head can bind two actin monomers. Biochem Biophys Res Commun 177, 350-356.

Barnett, L. A. \& Cunningham, M. W. (1992). Evidence for actinlike protein in a M protein-negative strain of Streptococcus pyogenes. Infect Immun 60, 3932-3936.

Bauman, P. \& Jackson, S. P. (1996). An archaebacterial homologue of the essential eubacterial cell division protein FtsZ. Proc Natl Acad Sci USA 93, 6726-6730.

Beck, B. D., Arschott, P. G. \& Jacobson, A. (1978). Novel properties of bacterial elongation factor Tu. Proc Natl Acad Sci USA 75, 1250-1254.

Bidlingmeyer, B. A., Cohen, S. A. \& Travin, T. L. (1984). Rapid analysis of amino acids using pre-column derivatization. $J$ Chromatogr 336, 93-104.

Bork, P., Sander, C. \& Valencia, A. (1992). An ATPase domain common to prokaryotic cell cycle proteins, sugar kinases, actin and hsp70 heat shock proteins. Proc Natl Acad Sci USA 89, 17290-17294.

Campos, A., Bernard, P., Fauconnier, A., Landa, A., Gómez, E., Hernández, R., Willms, K. \& Laclette, J. P. (1990). Cloning and sequencing of two actin genes from Taenia solium (Cestoda). Mol Biochem Parasitol 40, 87-93.

Casaregola, S., Norris, S., Goldberg, M. \& Holland, I. B. (1990). Identification of $180 \mathrm{kD}$ protein in Escherichia coli related to a yeast heavy chain myosin. Mol Microbiol 4, 505-511.

Flaherty, K. M., McKay, D. B., Kabsch, W. \& Holmes, K. C. (1991). Similarity of the three dimensional structure of actin and the ATPase fragment of $70 \mathrm{kDa}$ heat shock cognate protein. Proc Natl Acad Sci USA 88, 5041-5045.

Fleischmann, R. D., Adams, M. D., White, O. \& 37 other authors (1995). Whole-genome random sequencing and assembly of Haemophilus influenzae Rd. Science 269, 496-512.

Garrels, J. \& Gibson, W. (1976). Identification and characterization of multiple forms of actin. Cell 9, 793-805.

Göbel, U. (1983). Supramolecular structures in mycoplasmas. Yale J Biol Med 56, 695-700.

Guerrero-Barrera, A. L., Villalba, J., García, C., Segura, M., Gómez, C., Reyes, M., Hernández, M., García, R. \& De la Garza, M. (1995). Actin related proteins in the prokaryote Anabaena. Mol Biol Cell Suppl. 6, ASCB abstracts 19a, summary 111.
Guerrero-Barrera, A. L., García-Cuéllar, C. M., Villalba, J. D., Segura-Nieto, M., Hernández, J. M., Gómez-Lojero, C., Reyes, M. E., García, R. M. \& De la Garza, M. (1996). Actin-related proteins in Anabaena spp. and Escherichia coli. Microbiology 142, 1133-1140.

Haesebrouck, F., Chiers, K., Van Overbeke, I. \& Ducatelle, R. (1997). Actinobacillus pleuropneumoniae infections in pigs: the role of virulence factors in pathogenesis and protection. Vet Microbiol 58, 239-249.

Herman, I. M. (1993). Actin isoforms. Curr Opin Cell Biol 5, $48-55$.

Hiraga, S. (1993). Chromosome partition in Escherichia coli. Curr Opin Genet Dev 5, 789-801.

Kabsch, W. \& Holmes, K. (1995). The actin fold. FASEB J 9, 167-174.

Kabsch, W., Mannherz, H. G., Suck, D., Pai, E. F. \& Holmes, K. C. (1990). Atomic structure of actin DNase I complex. Nature 347, 33-44.

Koonin, E. V., Mushegian, A. R. \& Rudd, K. E. (1996). Sequencing and analysis of bacterial genomes. Curr Biol 4, 404-416.

Kreuder, V., Dieckhoff, J. \& Manherz, H. G. (1984). Isolation, characterization and crystallization of deoxyribonuclease I, from bovine and rat parotid gland and its interaction with rabbit skeletal muscle actin. Eur J Biochem 139, 389-400.

Labbé, J. P., Harricane, M. C., Boyer, M., Derancourt, J., Roustan, C. \& Benyamin, Y. (1996). Biochemical evidence for the presence of an unconventional actin protein in a prokaryotic organism. Comp Biochem Physiol B Biochem Mol Biol 114, 287-293.

Laemmli, U. K. (1970). Cleavage of structural proteins during the assembly of the head of bacteriophage T4. Nature 227, 680-685.

Lazarides, E. \& Lindberg, U. (1974). Actin is the natural occurring inhibitor of deoxyribonuclease I. Proc Natl Acad Sci USA 71, 4742-4746.

Lockhart, A. \& Kendrick-Jones, J. (1998). Nucleotide-dependent interaction of the terminal $\mathrm{N}$-domain of MukB with microtubules. J Struct Biol 15, 303-310.

Löwe, J. \& Amos, L. A. (1998). Crystal structure of the bacteria cell-division protein Fts-Z. Nature 391, 203-206.

Lu, C., Stricker, J. \& Ericson, H. P. (1998). FtsZ from Escherichia coli, Azotobacter vinelandii, and Thermotoga maritima: quantitation, GTP hydrolysis, and assembly. Cell Motil Cytoskeleton 40, 71-86.

Ma, X., Ehrhardt, D. W. \& Margolin, W. (1996). Colocalization of cell division proteins FtsZ and FtsA to cytoskeletal structures in living Escherichia coli cells by using green fluorescent protein. Proc Natl Acad Sci USA 93, 12998-13003.

Manjula, B. N. \& Fischetti, V. A. (1986). Sequence homology of group A streptococcal Pep M5 protein with other coiled-coil proteins. Biochem Biophys Res Commun 140, 684-690.

Manjula, B. N., Trus, B. L. \& Fischetti, V. A. (1985). Presence of two distinct regions in the coiled-coil structure of the streptococcal Pep M5 protein : relationship to mammalian coiled-coil proteins and implications to its biological properties. Proc Natl Acad Sci USA 82, 1064-1068.

Manjula, B. N., Khandke, K. M., Fairwell, T., Relf, W. A. \& Sriprakash, K. S. (1991). Heptad motifs within the distal subdomain of the coiled-coil rod region of $\mathrm{M}$ protein from rheumatic fever and nephritis associated serotypes of group A streptococci are distinct from each other: nucleotide sequence of the M57 gene and relation of the deduced amino acid sequence to other $M$ proteins. J Protein Chem 10, 369-384. 
Margolin, W. (1998). A green light for the bacterial cytoskeleton. Trends Microbiol 6, 233-238.

Mayer, F., Vogt, B. \& Poc, C. (1998). Immunoelectronmicroscopic studies indicate the existence of a cell shape preserving cytoskeleton in prokaryotes. Naturwissenschaften 85, 2278-2282.

Melby, T. E., Ciampaglio, C. N., Briscoe, G. \& Ericson, H. (1998). The symmetrical structure of structural maintenance of chromosomes (SMC) and MukB proteins: long, antiparallel coiled coils, folded at a flexible hinge. J Cell Biol 142, 1595-1604.

Minkoff, L. \& Damadian, R. (1976). Actin like protein from Escherichia coli. Concept of cytotonus has the missing link between cell metabolism and biological ion exchange resins. $J$ Bacteriol 125, 353-365.

Mische, S. M., Manjula, B. N. \& Fischetti, V. A. (1987). Relation of streptococcal M protein with human and rabbit tropomyosin: the complete amino acid sequence of human cardiac alpha tropomyosin, a highly conserved contractile protein. Biochem Biophys Res Commun 142, 813-818.

Miyamoto, Y., Kuroda, M., Munekata, E. \& Masaki, T. (1986). Stoichiometry of actin and phalloidin binding: one molecule of the toxin dominates two actin subunits. J Biochem (Tokyo) 100, 1677-1680.

Mullins, R. D., Kelleher, J. F. \& Pollard, T. D. (1996). Actin-like actin? Trends Cell Biol 6, 2208-2215.

Nakamura, K. \& Watanabe, S. (1978). Myosin and actin from Escherichia coli. J Biochem 83, 1459-1470.

Negrete-Abascal, E., Tenorio, V. R., Serrano, J. J., García, C. C. \& de la Garza, M. (1994). Secreted proteases from Actinobacillus pleuropneumoniae Serotype 1 degrade porcine gelatin, hemoglobin and immunoglobulin A. Can J Vet Res 58, 83-86.

Neimark, H. (1977). Extraction of an actin-like protein from the prokaryote Mycoplasma pneumoniae. Proc Natl Acad Sci USA 74, 4041-4054.

Niki, H., Imamura, R., Kitaoka, M., Yamanaka, K., Ogura, T. \& Hiraga, S. (1992). E. coli MukB protein involved in chromosomal partition forms a homodimer with a rod-and-hinge structure having DNA binding and ATP/GTP binding activities. EMBO J 11, 5101-5109.

Nogales, E., Wolf, S. G. \& Downing, K. H. (1998). Structure of the $\alpha \beta$ tubulin dimer by electron crystallography. Nature 391, 199-202.

Norris, V., Turnock, G. \& Sigee, D. (1996). The Escherichia coli enzoskeleton. Mol Microbiol 19, 197-204.

O'Farrel, P. H. (1975). High resolution two-dimensional electrophoresis of proteins. J Biol Chem 250, 4007-4021.

Pardee, J. D. \& Spudich, J. A. (1982). Purification of muscular actin. Methods Enzymol 85, 164-181.
Prideaux, C. T., Lenghaus, C., Krywult, J. \& Hodgson, A. L. M. (1999). Vaccination and protection of pigs against pleuropneumonia with a vaccine strain of Actinobacillus pleuropneumoniae produced by site-specific mutagenesis at the ApxII operon. Infect Immun 67, 1962-1966.

Rosenbusch, J. P., Jacobson, G. R. \& Jaton, J. C. (1976). Does a bacterial elongation factor share a common evolutionary ancestor with actin? J Supramol Struct 5, 391-396.

Sánchez, M., Valencia, A., Ferrándiz, J. M., Sander, C. \& Vicente, M. (1994). Correlation between the structure and biochemical activities of FtsA, an essential cell division protein of the actin family. EMBO J 13, 4919-4925.

Schägger, H. \& von Jagow, G. (1987). Tricine sodium dodecyl sulfate-polyacrylamide gel electrophoresis for the separation of proteins in the range from 1 to $100 \mathrm{kDa}$. Anal Biochem 166, 368-379.

Schroer, T., Fyberg, E., Cooper, J., Waterson, R., Helfman, D., Pollard, T. D. \& Meyer, D. (1994). Actin-related protein nomenclature and classification. J Cell Biol 127, 1777-1778.

Sharpe, M. E. \& Errington, J. (1999). Upheaval in the bacterial nucleoid. An active chromosome segregation mechanism. Trends Genet 15, 70-74.

Sheterline, P., Clayton, J. \& Sparrow, J. C. (1998). Actin-Protein Profile, 4th edn. New York: Oxford University Press.

Sioud, M., Baldacci, G., Forterre, P. \& Recondo, A. H. (1987). Antitumour drugs inhibit growth of halophylic archaebacteria. Eur J Biochem 169, 231-236.

Spudich, J. A. \& Watt, S. (1971). The regulation of rabbit skeletal muscle contraction. I. Biochemical studies of the interaction of the tropomyosin-troponin complex with actin and the proteolytic fragments of myosin. J Biol Chem 246, 4866-4871.

Usmanova, A., Astier, C., Méjean, C., Hubert, F., Feinberg, J., Benyamin, Y. \& Roustan, C. (1998). Coevolution of actin and associated proteins: an alpha-actinin-like protein in a cyanobacterium (Spirulina platensis). Comp Biochem Physiol B Biochem Mol Biol 120, 4693-4700.

Vandekerckhove, J., Deboben, A., Nassal, M. \& Wieland, T. (1985). The phalloidin binding site of F-actin. EMBO $J$, 2815-2818.

Wahl, R., Rice, P., Rice, C. M. \& Kröger, M. (1994). ECED - a totally integrated database of Escherichia coli K-12. Nucleic Acids Res 22, 3450-3455.

Wessel, D. \& Flügge, U. L. (1984). A method for the quantitative recovery of protein in dilute solution in the presence of detergents and lipids. Anal Biochem 138, 141-143.

Received 22 June 1999; accepted 22 July 1999. 